\title{
A New Approach for Extraction and Determination of Manganese in Environmental Samples Using Cloud-Point Extraction Coupled with Spectrophotometry
}

\author{
ZUHAIR A A KHAMMAS $^{* 1}$, SHAWKAT K. JAWAD ${ }^{2}$ and IBTEHAJ R.ALI ${ }^{1}$ \\ ${ }^{1}$ Department of Chemistry, College of Science for Women, University of Baghdad, Jadiryiah, \\ Baghdad, Iraq \\ ${ }^{2}$ Department of Chemistry, College of Education for women, University of Kufa, Kufa. \\ Najaf, Iraq \\ dr_zuhair52@yahoo.com
}

Received 2 January 2013 / Accepted 14 February 2013

\begin{abstract}
A new and versatile procedure for the spectrophotometric determination of manganese using micelle-mediated extraction was developed. The method involved the formation of an ion association complex between manganese oxyanion $\left(\mathrm{MnO}_{4}{ }^{-}\right)$and brilliant green in acidic solution and the complex was extracted into the surfactant Triton X-100 at optimum conditions. The surfactant-rich phase which contains manganese complex was mediated with solvent and the $\mathrm{Mn}$ content measured spectrophotometerically at absorption maximum $\left(\lambda_{\max }=657 \mathrm{~nm}\right)$. The effects of the several variables which impact the CPE efficiency were optimized by one-factor-at-a-time (OFAT). Under the optimized conditions, enrichment factor of 282 was achieved leading to limit of detection and limit of quantitation of 0.086 and $0.242 \mu \mathrm{g} \mathrm{mL}^{-1}$ respectively, with linearity of 0.2 $3 \mu \mathrm{g} \mathrm{mL}^{-1}$. The precision (RSD\%) of the proposed method was of $1.07 \%$. The interferences effect of such ions was also studied. This method is applicable in the determination of manganese in environmental and vital samples.
\end{abstract}

Keywords: Manganese oxyanion, Brilliant green, Cloud-point extraction, Spectrophotometry

\section{Introduction}

Manganese is well-known as both an essential and toxic trace element. As an essential, it is considered one of most important element in biochemistry which plays as co-factor for several enzymes. Mn contributes to maintain healthy nerves and immune system, helps in blood sugar regulation, involved in utilization of vitamins B1 and $\mathrm{E}$ and required for normal bone growth or for avoiding blood clotting defects ${ }^{1-2}$. Mn deficiency in human is rarely occurring owing to its widespread presence in the human diet, but if it is happening, causes the bones and cartilages deformation, destroys platelet aggregation, ataxia, osteoporosis, epilepsy and impaired growth ${ }^{3}$. However, at elevated Mn concentration, neurotoxicity occurs due to an accumulation of the metal in brain tissue causing an irreversible neurological 
syndrome similar to Parkinson's disease ${ }^{4}$. In this context, WHO recommends that the intake of $\mathrm{Mn}$ can be as high as $20 \mathrm{mg}$ /day without apparent ill effects, i.e. with an intake of 12 $\mathrm{mg}$ /day adult $(60 \mathrm{~kg})$ would receive $0.2 \mathrm{mg} / \mathrm{kg}$ of body weight per day ${ }^{5}$. Therefore, the determination of trace amounts of manganese in various samples is very significant for some fields, such as water, environmental and food matrices.

Trace manganese determination in such complex matrices is a challenge analytical task, mostly due to the low concentration of metal in these samples beside the matrix interferences, which requires sensitive instrumental techniques and often a pre-concentration step. Hence, separation and pre-concentration procedures before detection is a must to avoid the above dilemmas. Several separation and enrichment protocols coupled with different instrumental techniques for manganese assay have been developed include, precipitation/ $\mathrm{FAAS}^{6}$, solvent extraction/FAAS ${ }^{7}$, solid phase extraction/FAAS ${ }^{8}$ or solid phase extraction/ spectrophotometry ${ }^{9}$. Despite that each procedure has its merits and drawbacks, but the choice depends by virtue of analytical problem.

Recently, cloud point extraction (CPE) has intensively highlighted by many authors as a versatile and promising methodology for the separation and enrichment for metal ions and organic compounds from various matrices. Simply, in CPE, hydrophobic analytes is distributed between surfactant and aqueous phases and when the solution heated over a critical temperature of nonionic surfactant, called cloud point, the hydrophobic species are in a position to interact with the micelles thus being separated and concentrated in the small volume of surfactant-rich phase $^{10}$. This phase acts as an organic solvent with the extracted analyte partitioned between this phase and the aqueous solution containing only very small amounts of the dissolved surfactant ${ }^{11}$.

Since last decade, few articles have appeared in the chemical literatures reflect the applications merit of CPE coupled with atomic spectrometers for manganese extraction and preconcentration from water, saline water and food matrices. In all these attempts, the determination of manganese as a metal ion is based on the formation of hydrophobic chelates with commercial organic agents and extracted into micelle-mediated solvent, such as 1-(2-thiazolylazo)-2-naphthol(TAN) ${ }^{12}, 1$-(2-pyridylazo)-2-naphtol (PAN) and 1-(2-pyridylazo) -2-naphthol (PAN) ${ }^{13-14}, 1$-phenyl-3-methyl-4-benzoyl-5-pyrazolone (PMBP) ${ }^{15-16}, 2$ - $\left(2^{\prime}\right.$-thiazolylazo)- resorcinol (TAR) ${ }^{17}, 2-\left[2^{\prime}\right.$-(6-methyl-benzothiazolylazo)]-4-bromophenol( (Me-BTABr) ${ }^{18}$, nitrophenylazoresorcinol (Magneson I) ${ }^{19}$ and dithizone ${ }^{20}$.

The extraction and enrichment of metal ions as anionic metal complexes such as metal halo anions $\left(\mathrm{MX}_{4}^{-}\right)$and/or metal oxyanions $\left(\mathrm{MO}_{4}^{-}\right)$via the formation of ion-pairing complex with chromogenic reagents rather than chelating agents by using CPE coupled with UV-Vis spectrophotometry is a new trend toward establishing and developing in analytical methodology which will open the vast manners in easy, simple and inexpensive routine analysis instead of using costly instrumentations in this field. To the best of our knowledge, there is only one article was appeared in the chemical literatures based on the above concept for the determination of Cd (II) as $\mathrm{CdI}_{4}{ }^{2-}$ by combined CPE/ flame atomic absorption spectrometry since establishing of $\mathrm{CPE}^{21}$.

In this piece of work, a new approach was developed for the determination of manganese in soil, plant vegetable and meat samples by using CPE combined with UV-Vis spectrophotometry. The method is based on the formation of ion-paring hydrophobic complex between $\mathrm{MnO}_{4}^{-}$and Brilliant green (cationic dye) in acidic solution and subsequently extracted into the surfactant Triton X-100 at optimum conditions. The separated surfactant-rich phase was diluted with minimum amount of ethanol and manganese determined by UV-Vis spectromphotometry at $\lambda_{\max }$ of $657 \mathrm{~nm}$. The proposed method was applied for the determination of $\mathrm{Mn}$ in environmental and botanical samples 


\section{Experimental}

A Shimadzu double-bean UV-visible Spectrophotometer model UV-1700 (Japan) equipped with $10 \mathrm{~mm}$ optical path cell is used for the scanning study of absorption spectra of the complexes formed, while absorbance measurements were performed with Shimadzu singlebeam UV-Vis model UV-100.02 spectrophotometer model UV-100.02 (Japan). A Shimadzu atomic absorption spectrophotometer model AA6300 (Japan) is also used for the determination of manganese in the samples.

\section{Reagent and materials}

All analytical grade reagents were used without further purification as received from different company. Doubled distilled water was used for diluting the standard, reagents and samples. The nonionic surfactant (Triton $\mathrm{X}-100$ ) whose chemical structure is $\mathrm{C}_{8} \mathrm{H}_{17} \mathrm{C}_{6} \mathrm{H}_{4}$ $\left(\mathrm{OC}_{2} \mathrm{H}_{4}\right) n$ with $n$ equal to $9-10$ and an average molecular weight of $625 \mathrm{~g} / \mathrm{mol}$, was purchased from Sigma (Sigma Ultra, $>99.6 \%$ ). (UK) and used without further purification. Potassium permanganate (purity 99.0\%) and Brilliant green were purchased from CHEMSUPPLY Pty limited (Australian) and Merck respectively.

The stock solution of Mn (VII) at $1000 \mu \mathrm{g} \mathrm{mL}^{-1}$ was prepared by dissolving of $0.2877 \mathrm{~g}$ of $\mathrm{KMnO}_{4}$ in a minimum amount of water in $100 \mathrm{~mL}$ volumetric flask and completed to mark with water. Brilliant green solution of $1 \times 10^{-2} \mathrm{M}$ was prepared by dissolving $0.4827 \mathrm{~g}$ of Brilliant green in minimum amount of water in $100 \mathrm{~mL}$ volumetric flask and completed to mark with water. A $1 \%(\mathrm{w} / \mathrm{v})$ of triton $\mathrm{x}-100$ was prepared by dissolving $1 \mathrm{~g}$ of reagent in $100 \mathrm{~mL}$ of water.

\section{General CPE procedure}

$10 \mathrm{~mL}$ aliquots containing a proper amount of permanganate $\left(\mathrm{MnO}_{4}{ }^{-}\right)$standard or sample solution in $0.5 \mathrm{M} \mathrm{HCl}, 0.5 \mathrm{~mL}$ Brilliant green $\left(1 \times 10^{-2} \mathrm{M}\right)$ and $0.5 \mathrm{~mL}$ of $1 \%$ triton $\mathrm{x}-100$ were allowed to stand for $10 \mathrm{~min}$ in a thermostated bath at $80{ }^{\circ} \mathrm{C}$ to form cloud solution. Separation of the two phases were occurred immediately where the surfactant-rich phase became a highly viscous (without need of centrifugation and cooling) and settled down at the bottom of the tube making the aqueous phase easily discarded by simply inverting the tube. Later, the surfactant rich phase in the tube was dissolved in $5 \mathrm{~mL}$ of ethanol and the absorbance of the resulting solution was measured at $657 \mathrm{~nm}$ in a $1 \mathrm{~cm}$ cell against a reagent blank. The distribution ratio (D) and percent extraction $(\% \mathrm{E})$ were determined after the measurement of remaining quantity of $\mathrm{MnO}_{4}{ }^{-}$in aqueous to that extracted in micelle phase by using spectrophotometric method published elsewhere ${ }^{22}$.

\section{Preparation of samples}

Duplicate sample (soil, plant and meat) solutions were prepared by transferring approximately $2 \mathrm{~g}$ of dried sample into a $250 \mathrm{~mL}$ conical flask. Then, $4 \mathrm{~mL}$ of distilled water, $5 \mathrm{~mL}$ concentrated $\mathrm{H}_{2} \mathrm{SO}_{4}$ and $10 \mathrm{~mL}$ concentrated $\mathrm{HNO}_{3}$ were added. The content of the flask was heated gently on an electric hotplate for $10 \mathrm{~min}$ to ensure the destruction of all organic compounds in the sample. After cooling the solution, a little of water was added and then filtered. To each filtrated solution, $3 \mathrm{~mL}$ of concentrated sulfuric acid, $2 \mathrm{~mL}$ of concentrated phosphoric acid and $0.1 \mathrm{~g}$ of $\mathrm{KIO}_{4}$ were added and the contents heated to boiling for $10 \mathrm{~min}$ to oxidize all $\mathrm{Mn}$ (II) in the sample solution to $\mathrm{Mn}$ (VII). Thereafter, the contents were transferred into $50 \mathrm{~mL}$ volumetric flask and diluted to mark with water.

An aliquot of $5 \mathrm{~mL}$ of each sample solution was pipetted into $10 \mathrm{~mL}$ conical flask and treated with $0.1 \mathrm{~mL}$ of $1 \times 10^{-2} \mathrm{M}$ potassium thiocyanat solution as a masking agent and then 
filtered. The filtrated was transferred into $10 \mathrm{~mL}$ volumetric flask and diluted to mark with water from which the manganese content was extracted according to the general CPE procedure and determined by spectrophotometry at $\lambda_{\max }$ of $657 \mathrm{~nm}$. The blank solution was prepared in the same manner without analyte.

\section{Statistical analysis}

All statistical calculations, such as basic statistics, significance tests, regression equations and correlation coefficients for the calibration curves, were implemented using Minitab version 14 (Minitab Inc., State College, PA, USA) and Excel 2007(Microsoft Office ${ }^{\circledR}$ ).

\section{Results and Discussion}

\section{Absorption spectra}

Figure 1 shows the absorption spectra of the reagent brilliant green solution and its ionassociation complex with manganese oxyanion $\left(\mathrm{MnO}_{4}{ }^{-}\right)$in surfactant-rich phase against blank solution prepared under similar conditions were recorded using Shimadzu UV1700 equipped with $1 \mathrm{~cm}$ matched quartz cell. It was appeared that the absorption maximum $\left(\lambda_{\max }\right)$ of $\left[\mathrm{MnO}_{4}^{-}\right]\left[\mathrm{BG}^{+}\right]$ion association complex occurs in visible region at $657 \mathrm{~nm}$ while the reagent $\mathrm{BG}$ solution alone displays an absorption maximum at $\lambda_{\max }$ of $633 \mathrm{~nm}$. Therefore a wavelength maximum at $657 \mathrm{~nm}$ for the complex was used throughout this work.

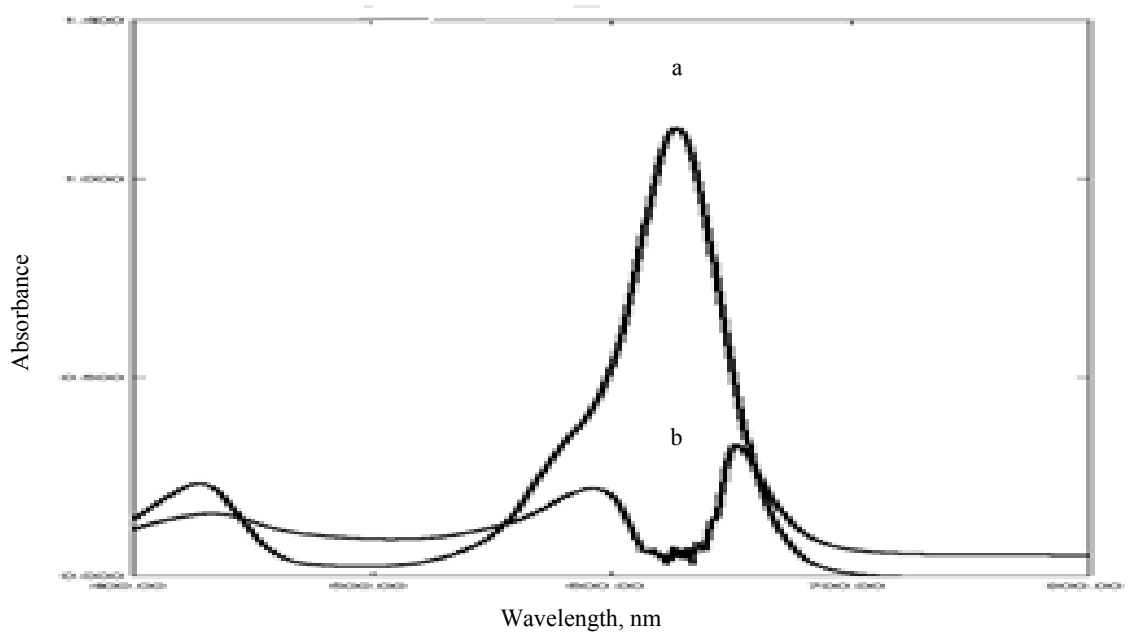

Figure 1. Absorption spectra of (a) $5 \times 10^{-4} \mathrm{M}$ Brilliant green (b) Mn-BG complex in micelle dissolved in ethanol.(Conditions: $20 \mu \mathrm{g} \mathrm{Mn}$ (VII) $0.5 \mathrm{M} \mathrm{HCl} ; 0.5 \mathrm{~mL}$ Brilliant green $\left(1 \times 10^{-2} \mathrm{M}\right)$; $0.5 \mathrm{~mL}$ of $1 \%$ triton $\mathrm{x}-100)$

\section{Optimization of CPE procedure}

The effects of several experimental parameters which impact the CPE efficiency were carried out by classical optimization (one-variable-at-a-time). In this approach, we observe the effect of one factor at a time (OVAT) on an experimental response. While only one factor is changed, others are kept at a constant level. Although, the "optimization" performed by $\mathrm{OVAT}^{23}$ does not ensure at all that the real optimum will be conformed, but it would be valid only if the variables to be optimized would be totally independent from each other (i.e. no interactive effects among the variables). Nevertheless, the classical optimization certainly leads at least to an improvement of the analytical method. In as much 
as the extraction efficiency of the CPE depends on dual factors, some of regarding the prior formation of a complex with sufficient hydrophobicity and the other for the formation of micelles to obtain the desired separation and pre-concentration. Consequently, the effects of $\mathrm{HCl}$, concentration of Brilliant green, nonionic surfactant Triton X-100 concentration and equilibration temperature and heating time were selected in this study.

\section{Effect of $\mathrm{HCl}$ concentration}

The separation of oxyanion $\left(\mathrm{MnO}_{4}^{-}\right)$by $\mathrm{CPE}$ method involves the formation of ion-association complex between $\left(\mathrm{MnO}_{4}^{-}\right)$and the protonated Brilliant green in the presence of $\mathrm{HCl}$, with sufficient hydrophobicity and extracted into micelle medium thus obtaining desired enrichment. In this study, $10 \mathrm{~mL}$ solution containing $20 \mu \mathrm{g} \mathrm{Mn}$ as $\mathrm{MnO}_{4}^{-}$, Brilliant green $\left(5 \times 10^{-4} \mathrm{M}\right)$ and $0.5 \mathrm{~mL}$ of $1 \%$ Triton $\mathrm{x}-100$ and varying concentration range of $0.1-1.0 \mathrm{M} \mathrm{HCl}$ was subjected to general CPE procedure. The results depicted in Figure $2(a, b)$ show the influence of $\mathrm{HCl}$ concentration on the absorbance and extractability of ion-association complex into the surfactant-rich phase. The absorbance signal reaches a maximum at $0.5 \mathrm{M}$ $\mathrm{HCl}$. At higher concentrations of $\mathrm{HCl}$, the absorbance suddenly decreases which most probably due to the reduction of permanganate(VII) ion to Mn(II) thus preventing the formation of ion-pair complex in micelle-mediated phase (Figure 2a). On the other hand, the distribution ratio (D) was also maximum at $0.5 \mathrm{M} \mathrm{HCl}$, indicating an adequate extraction efficiency of $\left[\mathrm{MnO}_{4}^{-}\right]\left[\mathrm{BG}^{+}\right]$ion-pair in water -nonionic surfactant phase system (Figure 2b).

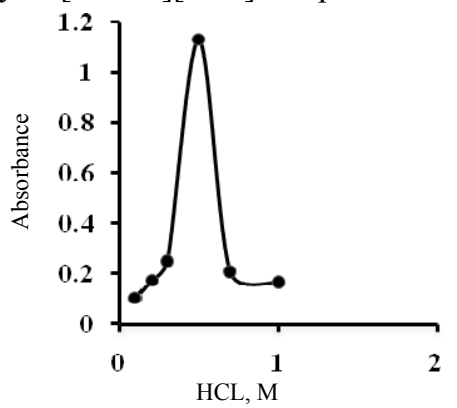

Figure 2a. Effect of $\mathrm{HCl}$

concentration on absorbance values

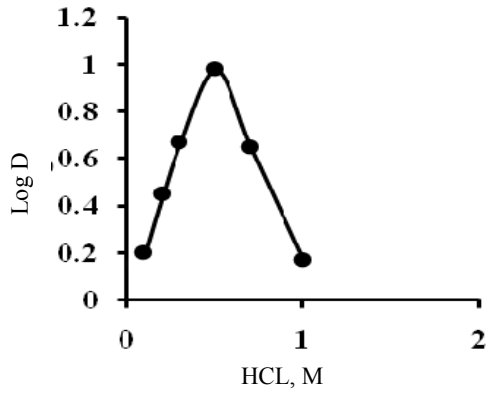

Figure 2b. The dependence of $\log$ $\mathrm{D}=f[\mathrm{HCl}]$

\section{Effect of brilliant green concentration}

The variation of absorption signal as a function of Brilliant green amount was investigated for $10 \mathrm{~mL}$ solution containing $20 \mu \mathrm{g} \mathrm{Mn}(\mathrm{VI}), 0.5 \mathrm{~mL}$ of Triton $\mathrm{x}-100(0.1 \%), 0.5 \mathrm{M} \mathrm{HCl}$ and varying volumes of $0.01-5 \mathrm{~mL}$ Brilliant green $\left(1 \times 10^{-2} \mathrm{M}\right)$ during CPE procedure. The results illustrated in Figure 3a have shown that the analytical response increased linearly with increasing in the amount of $\mathrm{BG}$ reagent and reached maximum up to $0.5 \mathrm{~mL}$ of $1 \times 10^{-2}$ $\mathrm{M} B \mathrm{BG}$ which is equivalent to $5 \times 10^{-4} \mathrm{M} \mathrm{BG}$, indicating sufficient for ion-pair complex formation. Thus a concentration of $5 \times 10^{-4} \mathrm{M}$ of $\mathrm{BG}$ was selected as optimum. This experiment was also conducted to obtain the distribution ratio (D) from the reminder quantity manganese as $\mathrm{MnO}_{4}^{-}$by spectrophotometric method ${ }^{22}$ and amount of transferred manganese as $\mathrm{MnO}_{4}^{-}$to form ion-pair complex into surfactant at the selected concentration of the reagent as shown in Figure $3 \mathrm{~b}$. The results also reveal that the concentration of $5 \times 10^{-4}$ M BG provides a high distribution ratio (D) with highly stable ion pair complex formation extractable into surfactant. At lower than $5 \times 10^{-5} \mathrm{M}$ BG, unstable ion-pair complex was formed which led to depress the extractability of ion pair complex into surfactant. 
It is also reported that the analysis of the dependence $\log \mathrm{D}=f\left(\log \mathrm{C}_{\mathrm{BG}}\right)$ permits the determination of the stiochoimetry in the extracted complex ${ }^{13}$. Consequently, the slope on the Figure $3 \mathrm{~b}$ in $\log \mathrm{D}=f\left(\log \mathrm{C}_{\mathrm{BG}}\right)$ coordinates is nearly equal to one, indicating the ion pair complex with $\mathrm{MnO}_{4}$ : $\mathrm{BG}$ ratio 1:1 is extracted into the surfactant-rich phase.

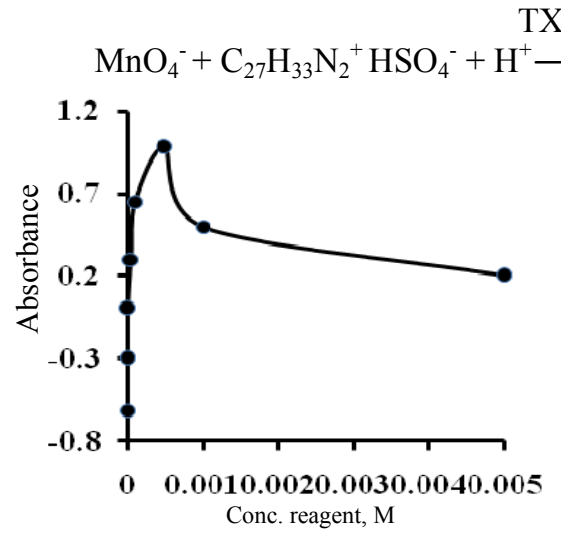

Figure 3a. Effect of BG concentration on extractability of ion-pair complex

TX-100

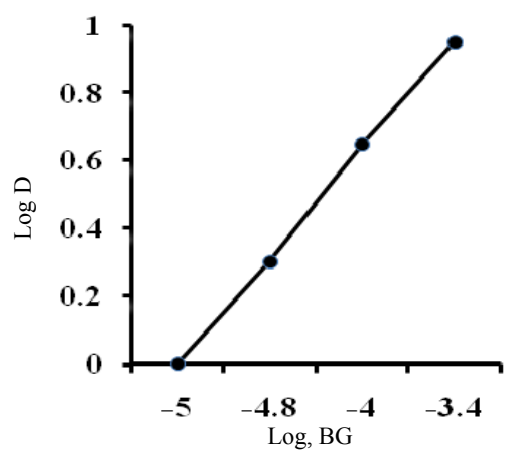

Figure 3b. $\log \mathrm{D}=f\left(\log \mathrm{C}_{\mathrm{BG}}\right)$

\section{Effect of surfactant concentration}

The effect of the surfactant amount on CPE of $10 \mathrm{~mL}$ containing $20 \mu \mathrm{g}$ Mn (VII) with $5 \times 10^{-4}$ $\mathrm{M} \mathrm{BG}$ at $0.5 \mathrm{M} \mathrm{HCl}$ in the presence of $1 \%$ Triton $\mathrm{x}-100$ varying from 0.1 to $1 \mathrm{~mL}$ has been optimized in order to obtain maximum extraction efficiency via minimizing the phase volume ratio. Figure $4 \mathrm{a}$ reflects the influence of Triton $\mathrm{x}-100$ amount on the preconcentration of Mn (VII). It was shown that the absorbance signal increases dramatically and reach maximum at $0.5 \mathrm{~mL}$ of $1 \%$ TritonX-100 and decreases suddenly thereafter. At low amount of surfactant, the absorbance and hence the distribution ratio (Figure $4 \mathrm{~b}$ ) for ion pair complex are low, perhaps due to the insufficiency of assemblies formation entrapping the complex quantitatively. Whilst at higher amount of surfactant, the extraction efficiency is low, probably due to the increase in surfactant-rich phase volume at which the analyte become more diluted resulting in poor sensitivity and thus valueless extraction efficiency. Consequently, optimum volume of $1 \%(\mathrm{w} / \mathrm{v})$ Triton $\mathrm{x}-100$ at $0.5 \mathrm{~mL}$ volume (equivalent to $0.05 \%$ Triton $\mathrm{x}-100$ in 10 $\mathrm{mL}$ test solution) was used in all experiments.

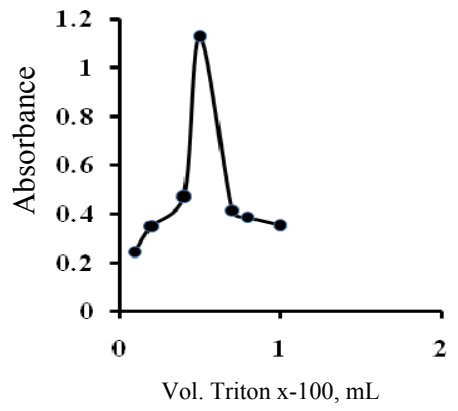

Figure 4a. Effect volume of Triton $\mathrm{x}-100$ on absorbance

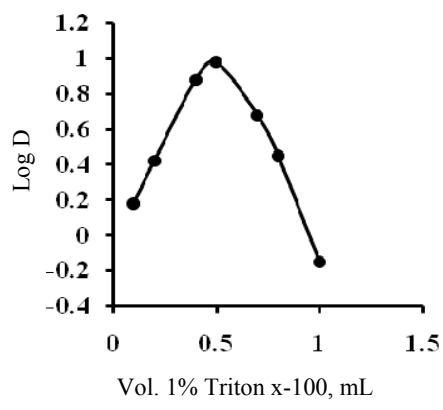

Figure 4b. Effect volume of Triton $\mathrm{x}-100$ on distribution ratio 


\section{Effect of the equilibration temperature and incubation time}

To ensure phase separation and preconcentration of an analyte efficiently, optimal equilibration temperature and time are very crucial parameters for complete reaction. The effects of the equilibrium temperature and the incubation time were examined due to their importance for the reaction completion and efficient separation of the phases, which reflect certainly the magnitude of preconcentration factor of an analyte. The temperature was varied from 70 to $80{ }^{\circ} \mathrm{C}$ in a search of optimum value. It was shown that the highest absorbance signals were obtained when the temperature at $80^{\circ} \mathrm{C}$ achieving quantitative extraction (Figure 5). Unreasonably high temperatures are not suitable for the CPE procedure because higher temperatures could cause problems to the stability of complex due to thermal decomposition of ion-association complex. In this study, $80^{\circ} \mathrm{C}$ was chosen as the optimized temperature for subsequent experiments. It was also observed that the incubation time of $10 \mathrm{~min}$ is sufficient for the maximum absorbance of manganese complex (Figure 6). Thus, the temperature of $80^{\circ} \mathrm{C}$ for $10 \mathrm{~min}$ was selected to fulfill efficient separation conditions.

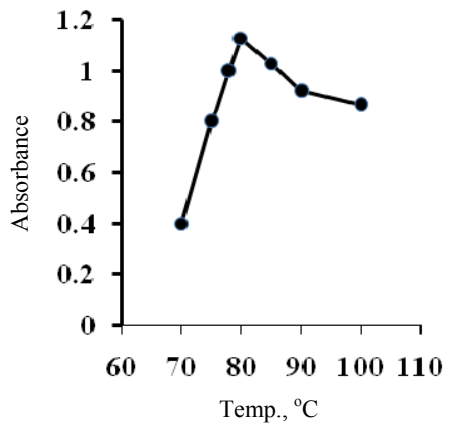

Figure 5. Effect of Temperature

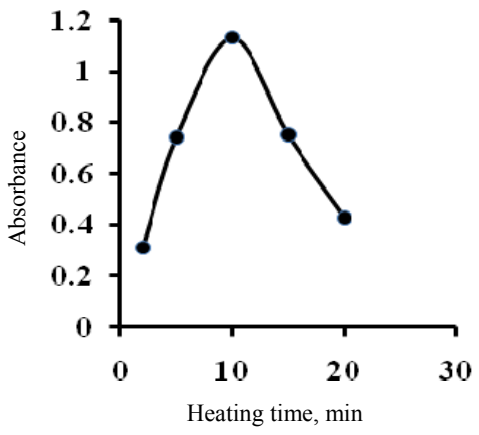

Figure 6. Effect of incubation time

\section{Thermodynamic study}

The equilibrium extraction constants $\left(\mathrm{K}_{\mathrm{ex}}\right)$ and thermodynamic parameters for the extraction of $\left[\mathrm{MnO}_{4}^{-}: \mathrm{BG}^{+}\right]$complex during the cloud point extraction using Triton $\mathrm{x}-100$ as a mediated extracting agent at various temperatures were determined. The equilibrium constants $\left(\mathrm{K}_{\mathrm{ex}}\right)$ at the selected temperature were calculated from equation below and the results are shown in Table 1 and Figure 7.

$$
\mathrm{K}_{\mathrm{ex}}=\frac{\mathrm{D}}{\left.[\mathrm{Mn}(\mathrm{VII})]_{\mathrm{aq}} . \mathrm{BG}\right]}
$$

These thermodynamic equilibrium constants $\left(\mathrm{K}_{\mathrm{ex}}\right)$ is actually represents all equilibrium constants that affect the separation process such as aggregation micelles constant with increasing temperature, complex transportation constant from aqueous phase to surfactant phase, association constant of the complex and distribution constant of the surface between aqueous phase and surfactant (micelles) phase.

Table 1. Variation of equilibrium constant with temperature during CPE

\begin{tabular}{ccccc}
\hline $\mathrm{T} \mathrm{C}^{0}$ & 70 & 75 & 78 & 80 \\
\hline $\mathrm{T} \mathrm{K}^{0}$ & 343 & 348 & 351 & 353 \\
$1 / \mathrm{T}$ & 2.92 & 2.87 & 2.85 & 2.83 \\
$\mathrm{~K}_{\mathrm{ex}}$ & $1.9054 \times 10^{8}$ & $3.4674 \times 10^{8}$ & $4.1687 \times 10^{8}$ & $5.248 \times 10^{8}$ \\
\hline
\end{tabular}




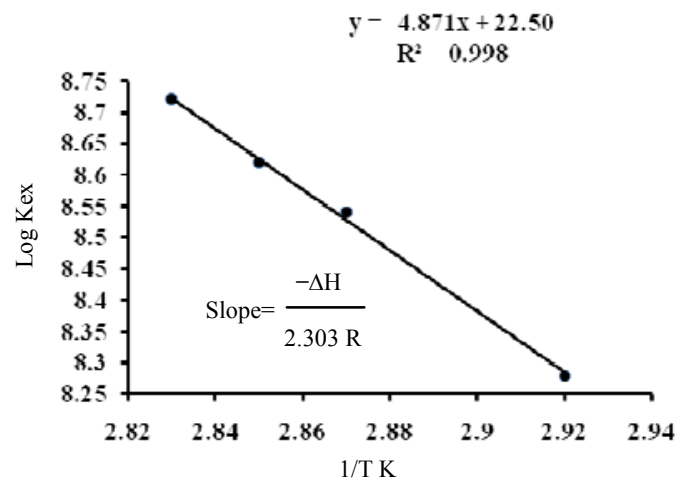

Figure 7. Effect of the equilibration extraction temperature on ion pair complex formation by $\mathrm{CPE}$

Thermodynamic parameters were also calculated from the relationships mentioned elsewhere ${ }^{24}$. The results are summarized in Table 2 . The value of enthalpy change $\left(\Delta \mathrm{H}_{\mathrm{ex}}\right.$ was obtained from the plot of $\log \mathrm{K}_{\mathrm{ex}}$ versus $1 / \mathrm{T}$ (Figure 7) and found to be $0.091 \mathrm{~kJ} \mathrm{~mol}^{-1}$ while the values of Gibb's free energy $\left(\Delta \mathrm{G}_{\mathrm{ex}}\right)$ and entropy change $\left(\Delta \mathrm{S}_{\mathrm{ex}}\right)$ were obtained at different temperatures from thermodynamic relationships.

Table 2. Thermodynamic parameters for the extraction of ion-pair complex by CPE

\begin{tabular}{cccc}
\hline$\stackrel{\mathrm{T},{ }^{0} \mathrm{~K}}{ }$ & $\Delta \mathrm{H}_{\mathrm{ex}}, \mathrm{kJ} \mathrm{mol}^{-1}$ & $\Delta \mathrm{G}_{\mathrm{ex}}, \mathrm{kJ} \mathrm{mol}^{-1}$ & $\Delta \mathrm{S}_{\mathrm{ex}}, \mathrm{J} \mathrm{mol}^{-1}$ \\
\hline 343 & & -54.3688 & 158.7749 \\
348 & 0.091 & -56.8932 & 163.5718 \\
351 & & -57.9215 & 165.2777 \\
353 & & -58.9116 & 167.1461 \\
\hline
\end{tabular}

It can be seen from Table 2 that the enthalpy change $\left(\Delta \mathrm{H}_{\mathrm{ext}}\right)$ is quite low and equal to $0.091 \mathrm{KJ} \mathrm{mol}^{-1}$ indicating a high efficiency of the extraction process of complex was achieved thermodynamically into the surfactant-rich phase. This is because (1) a strong electrostatic association exists between $\mathrm{MnO}_{4}{ }^{2-}$ anion with the reagent cation and (2) contribution of the complex in driving water molecules out of surfactant-rich phase in which more of micelles are aggregated enabling the precise extraction of complex especially in extracting of trace amounts. As for $\Delta \mathrm{G}_{\mathrm{ex}}$ is negative in all cases, indicating the extraction process is a spontaneous phenomena because the complex transportation and surfactant phase formation are synchronized processes occur at the same time. Thus the more negative value of $\Delta \mathrm{G}_{\mathrm{ex}}$, the large spontaneous process is. The positive values of $\Delta \mathrm{S}_{\mathrm{ex}}$ prove that the solubilized ion-association complex molecules are organized in more random fashion during extraction process. Therefore, the extraction process is endothermic in nature, which is also verified from the positive value of $\Delta \mathrm{H}_{\text {ext }}$ (Table 2).

\section{Effect kind of surfactant}

$10 \mathrm{~mL}$ of aqueous solution containing $20 \mu \mathrm{g} \mathrm{Mn}(\mathrm{VII}), 5 \times 10^{-4} \mathrm{M}$ Brilliant green, $0.5 \mathrm{M} \mathrm{HCl}$ and $0.5 \mathrm{~mL}$ of $1 \%$ of the selected surfactants is subjected to general CPE procedure. Figure 8 highlights the effect of different kinds of surfactants on the extractability of $\left[\mathrm{MnO}_{4}^{-}\right]$ $\left[\mathrm{C}_{27} \mathrm{H}_{33} \mathrm{~N}_{2}{ }^{+}\right]$complex. The results show Triton X-100 was the best non ionic surfactant for CPE of ion pair complex of $\mathrm{MnO}_{4}{ }^{-}$with $\mathrm{BG}$. From the other hand the, the presence of ether groups on structure of Triton $\mathrm{x}-100$ is more probable by sharing lone pair electron of which making 
the hydrogen bonding leading to significant increase of the micelles which reflect higher distribution ratio of the ion-pair complex in Triton $\mathrm{x}-100$ than in the other surfactants studied. While the other surfactants such as, Tween-80 and Tween-20 and SDS have shown that the formation of the separated surfactant-rich phase needs a higher temperature than $80^{\circ} \mathrm{C}$ and 15 min for Tween-20 and Tween- 80 except that SDS needs approximately $63{ }^{\circ} \mathrm{C}$ and $15 \mathrm{~min}$.

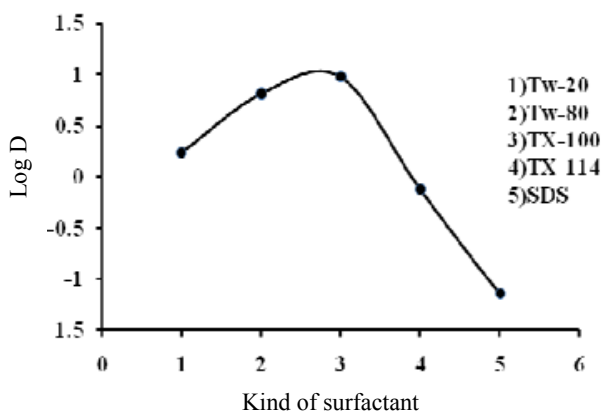

Figure 8. Effect of surfactant kinds on D value

\section{Effect of electrolyte salt}

It is known that the behavior of some electrolyte salt solutions lie in increasing the extraction percent during CPE process due to their act in increasing the dehydration of surfactant-rich phase. Table 3 reveals that some of electrolyte salts such as $\mathrm{LiCl}, \mathrm{MgSO}_{4}$, $\mathrm{NaNO}_{3}, \mathrm{Na}_{2} \mathrm{C}_{2} \mathrm{O}_{4}, \mathrm{CaCl}_{2}$ and $\mathrm{KNO}_{3}$ except $\mathrm{NH}_{4} \mathrm{NO}_{3}$ behave variably in decreasing the distribution ratio of ion association complex under extraction by CPE.

Table 3. Effect of some electrolyte salts on extractability of ion-association complex $(D=9.5$ and $\mathrm{Abs}=1.13$ ) upon addition of $0.2 \mathrm{M}$ of each salt

\begin{tabular}{ccc}
\hline Electrolyte salt & Abs. at 657 nm & D value \\
\hline $\mathrm{LiCl}$ & 0.432 & 3.60 \\
$\mathrm{MgSO}_{4}$ & 0.767 & 7.66 \\
$\mathrm{NaNO}_{3}$ & 0.568 & 5.30 \\
$\mathrm{NH}_{4} \mathrm{NO}_{3}$ & 1.29 & 16.5 \\
$\mathrm{CaCl}_{2}$ & 0.921 & 8.45 \\
$\mathrm{KNO}_{3}$ & 0.525 & 4.80 \\
\hline
\end{tabular}

This may be ascribed to the competition anions of these salts in formation of ionassociation complex with brilliant green cation rather than $\mathrm{MnO}_{4}^{-}$anion which lead to depression in extractability of $\left[\mathrm{MnO}_{4}^{-}\right]\left[\mathrm{BG}^{+}\right]$. On the contrary, ammonium nitrate gave a remarkable increment in the distribution ratio of interested complex because this salt has a great effect on dehydration of surfactant-rich phase due to the nature of electrolyte solution which may organize their ions inside surfactant-poor phase, leaving the ions of complex are more approaching together which contribute to concentrate ion-association complex in surfactant-rich phase and thereby the extractability was increased markedly.

\section{Method validation}

Under the optimized conditions, a linear calibration graph was obtained by plotting the absorbance signal against the concentration of $\mathrm{Mn}(\mathrm{VII})$. The calibration data are summarized in Table 4. The following regression equation was obtained: 


$$
\mathrm{y}=(0.565 \pm 0.0064) \mathrm{x}-(0.027 \pm 0.0115) r=0.9995 \text { and } n=7
$$

Where $\mathrm{y}$ is the absorbance and $\mathrm{x}$ is the manganese concentration in $\mu \mathrm{gmL}^{-1}$. This regression line had a coefficient of determination $\left(R^{2}\right)$ of $99.9 \%$, which suggests it is statistically valid. Analysis of variance (ANOVA) for the regression line was also carried out as shown in Table 5. ANOVA analysis supports that there is a strong significant relationship between the concentration of the analyte and absorbance units as $F_{t a b}=F_{1}$, ${ }_{6}=10.01<<7909.44$. Beer's law was obeyed over the concentration range $0.2-3 \mu \mathrm{g} \mathrm{mL}^{-1}$. The limit of detection (LOD) and limit of quantitation (LOQ) were of 085 and $0.282 \mu \mathrm{g} \mathrm{mL}^{-1}$ respectively, based on the standard deviation of the response and the slope of the calibration curve using the following equations; LOD $=3 \sigma_{\mathrm{B}} / \mathrm{s}$; LOQ $=10 \sigma_{\mathrm{B}} / \mathrm{s}$, where $\left(\sigma_{\mathrm{B}}\right)$ is the standard deviation of the calibration plot and (s) its slope. The limit of detection obtained was better than that obtained by Soto-Neira et al. $\left(22 \mu \mathrm{g} \mathrm{mL} \mathrm{m}^{-1}\right)$ using a new reagent (Cadmium(II) meso-Tetrakis (4-sulfophenyl) porphyrin complex) and derivative spectrophotometric method ${ }^{25}$. It is approximately close to that obtained by Kargosha and Noroozifar $\left(0.031 \mu \mathrm{g} \mathrm{mL}^{-1}\right)$ for speciation of manganese in aqueous solution by using flow injectionspectrophotometric method ${ }^{26}$. But, it was generally worse than that obtained by AAS, FIAAS and ICP-OES coupled with CPE ${ }^{14-15,17-18,27}$.

Table 4. Figures of merit for the determination of Mn by the proposed methods

\begin{tabular}{|c|c|}
\hline Parameter & value \\
\hline$\lambda_{\max }, \mathrm{nm}$ & 657 \\
\hline Regression equation with CPE procedure & $y=0.565 x-0.027$ \\
\hline Correlation coefficient(r) & 0.9995 \\
\hline Coefficient of determination $\left(\mathrm{R}^{2}\right)$ & $99.9 \%$ \\
\hline C.L. for the slope ( $b \pm t s b)$ at $95 \%$ & $0.565 \pm 0.01632$ \\
\hline C.L. for the intercept ( $a \pm$ tsa) at $95 \%$ & $-0.027 \pm 0.02945$ \\
\hline Concentration range, $\mu \mathrm{g} \mathrm{mL}^{-1}$ & $0.2-3$ \\
\hline Limit of detection, $\mu \mathrm{g} \mathrm{mL}^{-1}$ & 0.086 \\
\hline Limit of quantitation, $\mu \mathrm{g} \mathrm{mL}^{-1}$ & 0.282 \\
\hline Sandell's sensitivity, $\mu \mathrm{g} \mathrm{cm}^{-2} / 0.001 \mathrm{~A} . \mathrm{U}$ & $1.16 \times 10^{-7}$ \\
\hline Molar absorptivity, L. $\mathrm{mol}^{-1} \cdot \mathrm{cm}^{-1}$ & $5.5 \times 10^{4}$ \\
\hline Composition of complex (M: L) ${ }^{*}$ & $1: 1$ \\
\hline $\mathrm{RSD} \%(\mathrm{n}=7)$ at $2 \mu \mathrm{g} \mathrm{mL}^{-1}$ & 1.07 \\
\hline Preconcentration factor $^{* *}$ & 200 \\
\hline Enrichment factor $^{* * *}$ & 280 \\
\hline
\end{tabular}

*Obtained by slope analysis method, ${ }^{* *}$ Calculated as the ratio of the original sample volume to that of extracted volume, ${ }^{* * *}$ Calculated as the ratio of slope of calibration curve obtained by CPE to that obtained without preconcentration

Table 5. Analysis of Variance of regression line

\begin{tabular}{ccccc}
\hline Source & DF & SS & MS & F \\
\hline Regression & 1 & 2.05227 & 2.05227 & 7909.44 \\
Residual Error & 5 & 0.00130 & 0.00026 & \\
Total & 6 & 2.05357 & & \\
\hline
\end{tabular}

$D F=$ degrees of freedom, SS: sum of squares, MS: mean of squares, F(Fisher F-test)

This is evident due to the detection restrictions of UV-Vis spectrophotometry comparing with above the most sensitive techniques. By considering a limit of detection of $86 \mu \mathrm{g} \mathrm{L}^{-1}$ and $2 \mathrm{~g}$ of sample in $50 \mathrm{~mL}$, the LOD of the method would be $2.15 \mu \mathrm{g} \mathrm{g}^{-1}$. On that 
basis the proposed method was applied for the determination of manganese in various samples including soils, plants (vegetable and leaves) and meat selected randomly from different areas of the Najaf City (middle of Iraq) in order to test its applicability and reliability.

\section{Determination of manganese in real samples}

The proposed method was applied to the determination of manganese in soil, vegetables, crops and meat samples. Each sample was treated according to digestion procedure explained in experimental work and all manganese was oxidized into $\mathrm{Mn}(\mathrm{VI})$, preconcetrated by recommended CPE procedure and detected spectrophotometrically at 657 $\mathrm{nm}$. The samples were also analyzed by a standard atomic absorption spectrometry (FAAS) method and the results were compared. The results are presented from Table 6 to Table 9.

Table 6. Mn content $\left(\mu \mathrm{g} \mathrm{g}^{-1}\right)$ in the non-agriculture soil samples from different areas of the Najaf City (middle of Iraq).

\begin{tabular}{lcc}
\hline Sample & $\begin{array}{c}\text { Proposed } \\
\text { method }\end{array}$ & AAS method \\
\hline Al-Muthana street near street & $56.0 \pm 0.135$ & $55.0 \pm 0.236$ \\
Al-Ashreen & $42.4 \pm 0.166$ & $39.9 \pm 0.122$ \\
Al-Mufeed street & $48.0 \pm 0.141$ & $45.6 \pm 0.179$ \\
Al-Rawan street & $54.2 \pm 0.085$ & $53.3 \pm 0.311$ \\
Al-Abasiat & $65.0 \pm 0.189$ & $66.0 \pm 0.231$ \\
Al-Muthana street far -off street & $54.4 \pm 0.147$ & $53.7 \pm 0.056$ \\
$\bar{X}_{\mathrm{d}}$ & 0.867 & \\
$\mathrm{~S}_{\mathrm{d}}$ & 1.461050 & \\
$\mathrm{t}_{\text {cal }(\mathrm{n}=6)}$ & 1.45 & \\
$\mathrm{t}_{\text {crit. }}$ at 95\% DF=5 & 2.57 & \\
$\mathrm{P}-\mathrm{value}$ & 0.206 & \\
\hline
\end{tabular}

Table 7. Mn content $\left(\mu \mathrm{g} \mathrm{g}^{-1}\right)$ in the agriculture soil samples (most of near of the rivers) of the Najaf City (middle of Iraq)

\begin{tabular}{llc}
\hline Sample & $\begin{array}{c}\text { Proposed } \\
\text { method }\end{array}$ & AAS method \\
\hline Near Kufa river & $66.0 \pm 0.162$ & $65.0 \pm 0.214$ \\
Al-Huria & $76.0 . \pm 0.233$ & $74.5 \pm 0.198$ \\
Al-shamia & $64.0 \pm 0.264$ & $65.0 \pm 0.209$ \\
Shamia & $58.0 \pm 0.186$ & $56.0 \pm 0.322$ \\
Abarat & $60.0 \pm 0.067$ & $60.0 \pm 0.259$ \\
Abasia & $24.0 \pm 0.125$ & $23.0 \pm 0.147$ \\
Heara & $16.0 \pm 0.269$ & $15.0 \pm 0.359$ \\
Al-Mashkab & $72.0 \pm 0.311$ & $71.5 \pm 0.402$ \\
$\overline{\mathrm{X}}_{\mathrm{d}}$ & & \\
$\mathrm{S}_{\mathrm{d}}$ & 0.750 & \\
$\mathrm{t}_{\text {cal(n=6) }}$ & 0.925820 & \\
$\mathrm{t}_{\text {crit. }}$ at $\%$ DF $=7$ & 2.29 & \\
$\mathrm{P}-$ value & 2.36 & \\
\hline
\end{tabular}


Table 8. Mn content ( $\mu \mathrm{g} \mathrm{g}^{-1}$ in plants and vegetable samples of the Najaf City (middle of Iraq).

\begin{tabular}{llc}
\hline Sample No. & Proposed method & AAS method \\
\hline Solanum melongena & $13.6 \pm 0.413$ & $12.5 \pm 0.266$ \\
Potato & $46.0 \pm 0.287$ & $45.0 \pm 0.373$ \\
Tomato & $56.0 \pm 0.258$ & $55.0 \pm 0.421$ \\
Aplum gravealens & $80.0 \pm 0.228$ & $78.4 \pm 0.277$ \\
Iraqi dates & $56.0 \pm 0.319$ & $55.0 \pm 0.139$ \\
Cucumbers & $20.0 \pm 0.309$ & $18.8 \pm 0.212$ \\
Capsicum sp & $4.0 \pm 0.1099$ & $3.30 \pm 0.227$ \\
Vicitoria regia & $10.0 \pm 0.157$ & $12.0 \pm 0.355$ \\
$\overline{\mathrm{X}}_{\mathrm{d}}$ & & \\
$\mathrm{S}_{\mathrm{d}}$ & 0.700 & \\
$\mathrm{t}_{\text {cal }(\mathrm{n}=6)}$ & 1.119949 & \\
$\mathrm{t}_{\text {crit. }}$ at $95 \% \mathrm{DF}=7$ & 1.77 & \\
$\mathrm{P}$-value & 2.36 & \\
\hline
\end{tabular}

Table 9. Mn content $\left(\mu \mathrm{g} \mathrm{g}^{-1}\right)$ in meat samples

\begin{tabular}{lcc}
\hline Sample No. & Proposed method & AAS method \\
\hline Beef(Indian) & $12.8 \pm 0.288$ & $11.9 \pm 0.214$ \\
Beef (Iraqi) & $12.2 \pm 0.328$ & $12.0 \pm 0.056$ \\
Chicken(Brazilian) & $9.2 \pm 0.328$ & $8.7 \pm 0.0940$ \\
Tween-20 & $5.8 \pm 0.244$ & $5.2 \pm 0.208$ \\
Chicken(Iraqi) & $2.8 \pm 0.269$ & $2.0 \pm 0.361$ \\
fish(Iraqi) & & \\
$\overline{\mathrm{X}}_{\mathrm{d}}$ & 0.400 & \\
$\mathrm{~S}_{\mathrm{d}}$ & 0.353553 & \\
$\mathrm{t}_{\text {cal(n=5) }}$ & 2.53 & \\
$\mathrm{t}_{\text {crit. }}$ at 95\% DF=4 & 2.78 & \\
$\mathrm{P}_{-}$Value & 0.065 & \\
\hline
\end{tabular}

All statistical results performed by the paired $t$-test ${ }^{28}$ for comparison of means between the proposed and standard AAS methods for all samples (Table 6-9) have shown that all $\mathrm{p}$ values $[\mathrm{P}(\mathrm{T}<\mathrm{t})$ two tailed] based on the $5 \%$ critical values $(t$-two tailed) were more than the $|\mathrm{t}|$ calculated values indicating acceptance of null hypothesis $\left(\mathrm{H}_{\mathrm{o}}\right)$ which specified that there appears insufficient evidence to suggest the accuracy of the established CPEspectrophtometry differs with that of standard AAS method (i.e. there is a good agreement between the results obtained by the two methods).

\section{Conclusion}

In this piece of work, a new avenue has been exploited for the extraction and determination of manganese in the form of oxyanion that reacts with an organic reagent to form ionassociation complex by combined CPE-spectrophotometric method, for the purpose of developing the features and analytical capability of CPE in inorganic anion analysis rather than that of the previously reported for metal chelate extraction by using CPE. Although, thermodynamic study and effect of some parameters gave encouraging results, but more 
works would require investigating the behavior of solubilization of inorganic anions in the micelle phase. The proposed procedure also permits to increase the popularity of UV-Vis speectrophotometric technique after CPE beside the solvent-free extraction for metal ions from complex matrices which proved to be fairly accurate and thereby it might be considered as an alternative for atomic spectrometric techniques.

\section{References}

1. Leach R M and Lilburn M S, World Review of Nutrition and Dietetics, 1989, 32, 123-134.

2. MichalkeI B, J Chromatogr A, 2005, 1050(1), 69-76.

3. Ryenold C V, Alarco N M A, Lopez H, La Serrana D, Valero V P and LopezMartinez M C, Food Chem., 2008, 109(1), 113-121.

4. Crossgrove J and Zheng W, NMR Biomedicine, 2004, 17(8), 544-553.

5. World Health Organization; International Programme on Chemical Safety (IPCS) Guidelines for drinking water quality: Health criteria and other supporting information, Geneva, CH; $2^{\text {nd }}$ Ed., 1996, 2, 31-388.

6. Dittfurth C, Ballesteros E, Gallego M and Valcgrcel M, Spectrochim Acta B: Atomic Spectroscopy, 1996, 51(14), 1935-1941.

7. Shukla R and Rao G N, Talanta, 2002, 57(4), 633-639.

8. Baytak S and Turke A R, Talanta, 2005, 65(4), 938-945.

9. Dogutan M, Filik H and Apak R, Anal Chim Acta, 2003, 485(2), 205-212

10. Szymanowski J, J Radioanal Nucl Chem., 2000, 246(3), 635-642.

11. Chen J and Toe K C, Anal Chim Acta, 2001, 450(1-2), 215-222.

12. Teo K C and Chen J, Analyst, 2001, 126(4), 534-537.

13. Doroschuk V O, Lelyushok S O, Ishchenko V B and Kulichenko S A, Talanta, 2004, 64(4), 853-856.

14. Rod A R and Shemirani B and Farzaneh S, Eur Food Res Technol., 2006, 223(5), 649-653.

15. Liang P, Sang H and Sun Z, J Colloid Interface Sci., 2006, 304(2), 486-490.

16. Sun Z, Liang P, Ding Q and Jing C A O, Anal Sci., 2006, 22, 911-913.

17. Bezerra de M A, Conceicao A L B and Ferreira S L C, Microchim Acta, 2006, 154(1-2), 149-152.

18. Lemos V A and David G T, Microchem J., 2010, 94(1), 42-47.

19. Şahin C A, Efecinar M and Şatıroğlu N, J Hazard Mater., 2010, 176(1-3), 672-677.

20. Bezerra M A, do Nascimento Maêda S M, Oliveira E P, de Carvalho M F B and Santelli R E, Spectrochim Acta Part B, 2007, 62(9), 985-991.

21. Dadfarnia S, Mohammad A, Shabani H and Kamranzadeh E, J Braz Chem Soc., 2010, 21(12), 2353-2358 .

22. Marczenko Z, Separation and spectrophotometeric determination of elements, Copyring by Allis Horoodo limited, 1974.

23. Leardi R, Anal Chim Acta, 2009, 652(1-2), 161-172.

24. Atkine P W, Physical Chemistry, $5^{\text {th }}$ Edition. Oxford University, United Kingdom. 1994.

25. Soto-Neira J, Zhu Q and Aller R C, Marine Chem., 2011, 127(1-4), 56-63.

26. Kargosha K and Noroozifar M, Turk J Chem., 2003, 27, 227-233.

27. Lemos V A, Baliza P X, de Carvalho A L, Oliveira R V, Teixeira L S G and Bezerra M A, Talanta, 2008, 77(1), 388-393.

28. Minitab ${ }^{\circledR}$ Statistical Software 14, State College, Pennsylvania, USA, 2011. 